\title{
EKSPLORASI ETNOMATEMATIKA PADA RAGAM CORAK UKIRAN KHAS MELAYU KEPULAUAN RIAU
}

\author{
Siti Nurhikmah ${ }^{1}$, Febrian $^{2}$, Mirta Fera $^{3}$ \\ ${ }^{1,2,3}$ Universitas Maritim Raja Ali Haji, Kota Tanjungpinang, Kepuluaan Riau 19125, Indonesia
}

Pengiriman: 21 Mei 2019; Diterima: 23 Juni 2019; Publikasi: 28 Juli 2019

\begin{abstract}
Abstrak
Penelitian ini merupakan penelitian etnografi yang bertujuan untuk mendeskripsikan hasil eksplorasi etnomatematika ragam corak ukiran khas Melayu Kepulauan Riau. Penelitian ini dilaksanakan pada bulan Mei 2018 hingga Agustus 2018 di Pulau Penyengat. Objek penelitian ini adalah corak ukiran khas Melayu Kepulauan Riau. Teknik pengumpulan data yang digunakan yaitu metode observasi, wawancara dengan narasumbernya Bapak Said Usman dan dokumentasi. Instrumen yang digunakan yaitu instrumen utama dengan berbantuan instrumen pendamping yaitu lembar observasi dan wawancara. Penentuan sumber data dengan menggunakan teknik purposive sampling yaitu pengambilan sampel dengan pertimbangan tertentu. Teknik analisis data yang digunakan yaitu analisis domain, taksonomi, komponensial dan tema budaya. Pengukuran keabsahan data dilakukan dengan perpanjangan pengamatan, peningkatan ketekunan dan triangulasi teknik pengumpulan data. Hasil penelitian menunjukkan bahwa terdapat konsep matematika sekolah pada ragam corak ukiran khas Melayu Kepulauan Riau yang dapat diterapkan dalam pembelajaran matematika di sekolah yaitu : bangun datar dan bangun ruang, pecahan, perbandingan, kongruenan, simetri dan transformasi geometri.
\end{abstract}

Kata Kunci: etnomatematika ragam corak ukiran; khas Melayu Kepulauan Riau; konsep matematika

\begin{abstract}
This research is an ethnographic study which aims to describe the results of ethnomathematics exploration of various carvings typical of the Malay Riau Island. This research was conducted in May 2018 to August 2018 at Penyengat Island. The object of this research is typical Malay Archipelago carving patterns. Data collection techniques used is observation method, interviews with informant is Mr. Said Usman and documentation method. The instruments used were the main instruments assisted by accompanying instruments is observation sheets and interviews. Determination of data sources using purposive sampling technique that is sampling with certain considerations. The data analysis techniques used are domain analysis, taxonomic analysis, compound analysis and cultural theme analysis. The validity of data is measured by an extension of observation, increased persistence and triangulation of data collection techniques. The results showed that there was a school mathematical concept in a variety of distinctive Malay-style Riau Islands carvings that could be applied in learning mathematics in schools, namely: building flat and building space, fractions, comparisons, congruence, symmetry and geometric transformation.
\end{abstract}

Keywords: Ethnomatematics of various carving patterns; Typical Malay Riau Island; mathematical concepts

\section{PENDAhuluan}

Terbentuknya Provinsi Kepulauan

Riau berawal dari terpecahnya Riau Daratan dan Riau Kepulauan. Riau Daratan kini lebih dikenal dengan sebutan Provinsi Riau

*Penulis Korespondensi

Email Adress : Snurhikmah.sn@gmail.com sedangkan Riau Kepulauan yang kini lebih dikenal dengan sebutan Provinsi Kepulauan Riau (KEPRI) yang telah berdiri sendiri dan sejauh ini memiliki tujuh Kabupaten atau Kota dan berpusat di Kota Tanjungpinang. 
Perpindahan ibukota dulunya dari Tanjungpinang ke Pekanbaru telah membawa dampak buruk bagi pulau-pulau yang memiliki sektor-sektor penghidupan seperti pendidikan, kesehatan, pertanian, perkebunan, dan industri. Namun keterpurukan tersebut perlahan membaik dengan adanya potensi budaya lokal yang dimiliki Kota Tanjungpinang.

Pulau Penyengat yang merupakan salah satu bagian dari pulau-pulau yang ada di Kota Tanjungpinang ini sangat dikenal sebagai tempat bersejarah dan sekaligus sebagai aset daerah. Tempat ini menjadi pusat bersejarah yang tersohor dari dulu karena beberapa peninggalan sejarah Kepulauan Riau dijaga sebaik mungkin disana. Dan hingga saat ini pun, Pulau Penyengat menjadi tempat wisata khususnya bagi seluruh masyarakat Tanjungpinang dan juga dari berbagai penjuru negara yang datang dan berkunjung ke Pulau Penyengat.

Selain sebagai tempat wisata, Pulau Penyengat juga dikenal memiliki ragam budaya Melayu. Salah satunya ragam corak ukiran khas Melayu Kepulauan Riau yang biasanya menjadi hiasan di setiap bangunan atau rumah-rumah adat Melayu di Kepulauan Riau. Corak khas tersebut sering dijadikan hiasan rumah seperti jendela, pintu, ventilasi, atap, maupun pagarnya. Namun hal ini sudah jarang terlihat di beberapa bangunan baru yang ada di Pulau Penyengat. Karena masih kurangnya rasa cinta masyarakat terhadap budaya lokal yang mereka miliki dan juga ketidaktahuan mereka tentang potensi apa yang sebenarnya tertanam dalam corak ukiran khas Melayu sehingga jarang sekali adanya eksplorasi mengenai potensi-potensi budaya tersebut apabila ditinjau lebih lanjut dari aspek intelektualitas budaya setempat. Salah satu tolak ukurnya adalah aktivitas matematis yang mungkin ada dalam praktek kehidupan masyarakat. Hal ini sering dikenal dengan istilah etnomatematika.

Istilah etnomatematika pertama kali dikemukakan oleh D'Ambrosio (1984) dalam Laurens (2016) seorang matematikawan Brazil dengan pendefinisian sebagai berikut: "Ethnomathematics is the way different cultural groups mathematise (count, measure, relate, classify, and infer)". Menurutnya imbuhan ethno menjelaskan semua fenomena yang membentuk identitas budaya yang dikelompokkan sebagai bahasa, kode, nilai, dialek, keyakinan, makanan dan pakaian serta kebiasaan dan perilaku. Kata mathematics menjelaskan pandangan yang luas tentang matematika termasuk perhitungan atau pemecahan, aritmatika, pengklasifikasian, pengurutan, pengambilan keputusan dan pemodelan.

Menurut Turmudi dalam Prabawati (2016) juga menyatakan bahwa matematika berurusan dengan gagasan, matematika bukan tanda-tanda sebagai akibat dari coretan pensil, bahkan kumpulan bendabenda fisik berupa segitiga, namun berupa gagasan yang direpresentasikan oleh bendabenda fisik. Hal ini menunjukkan bahwa dalam mempelajari matematika bukan saja harus bersifat terpaku pada tulisan tetapi juga perlu adanya sebuah sumber informasi visual yang dapat membantu proses pengenalan konsep matematika yang lebih efektif. Sehingga matematika yang tumbuh dalam budaya akan memberikan kontribusi yang besar sesuai dengan Kurikulum 2013 yang berlaku sekarang.

Menurut Mulyasa (2015: 59) dalam suatu sistem pendidikan, kurikulum itu sifatnya dinamis serta harus selalu dilakukan perubahan dan pengembangan agar dapat 
mengikuti perkembangan dan tantangan zaman dan perubahannya pun harus dilakukan secara sistematis dan terarah. Sehingga perubahan dan pengembangan Kurikulum 2013 harus mampu membekali para siswa dengan berbagai kompetensikompetensi yang diperlukan sesuai dengan perkembangan global. Untuk itu, Kurikulum 2013 ini dilakukan agar dapat mengatasi berbagai tantangan masa depan yang semakin lama semakin rumit akibat pengaruh zaman karena pesatnya teknologi informasi yang mampu memudarkan bahkan menghilangkan budaya yang ada. Oleh karena itu, perlunya pengkajian tentang sejauh mana aktivitas matematika yang tertanam dibalik khazanah budaya ragam corak ukiran khas Melayu di Kepulauan Riau. Penelitian ini juga diharapkan dapat menumbuhkan kembali rasa cinta budaya lokal dan dijadikan sebagai alternatif baru serta membangun rasa kreativitas bagi para guru dalam menerapkan pembelajaran yang lebih baik, unik dan konkret dalam memanfaatkan budaya yang ada sesuai dengan konsep matematika sekolah pada Kurikulum 2013. Siswa juga dapat belajar matematika sambil mengetahui dan mencintai budayanya sendiri. Seperti dalam pepatah "sekali dayung dua pulau terlampaui".

Selain itu, menurut Rachmawati (2012) pendidikan di Indonesia masih tergolong rendah karena kurangnya kemampuan matematika siswa dalam menyelesaikan soal penalaran dalam pemecahan masalah akibat kurangnya pemberian porsi menalar dan memecahkan masalah pada materi ajar dan soal-soal latihan kepada siswa. Hal ini disebabkan oleh adanya kehawatiran kurang mampunya siswa dalam menerapkan matematika untuk menyelesaikan masalah dalam kehidupan sehari-hari. Sudah semestinya mengupayakan berbagai cara dan meningkatkan kreativitas dalam rangka meningkatkan kemampuan matematika siswa. Salah satu kuncinya adalah harus adanya perbaikan proses pembelajaran matematika di sekolah, khususnya dengan meningkatan porsi menalar, memecahkan masalah, berargumentasi dan berkomunikasi melalui materi ajar yang lebih kontekstual.

Oleh karena itu, perlunya mengeksplorasi lebih dalam tentang sejauh mana konsep matematika sekolah yang tertanam dibalik khazanah budaya ragam corak ukiran khas Melayu di Kepulauan Riau. Penelitian ini juga diharapkan dapat menumbuhkan kembali rasa cinta budaya lokal dan dijadikan sebagai alternatif baru serta membangun rasa kreativitas bagi para guru dalam menerapkan pembelajaran yang lebih baik, unik dan konkret dalam memanfaatkan budaya yang ada sesuai dengan konsep matematika sekolah dan siswa pun bisa belajar matematika sambil mengetahui dan mencintai budayanya sendiri.

\section{METODE PENELITIAN}

Penelitian ini dilaksanakan selama empat bulan pada bulan Mei hingga Agustus 2018 di Pulau Penyengat. Jenis penelitian ini adalah penelitian kualitatif berdesain etnografi yang bertujuan untuk mengeksplorasi etnomatematika ragam corak ukiran khas Melayu Kepulauan Riau. Objek penelitian ini adalah corak ukiran khas Melayu Kepulauan Riau. Instrumen yang digunakan adalah human instrument dan instrumen pendamping (lembar observasi dan lembar wawancara) dengan menggunakan teknik pengumpulan data yaitu observasi, wawancara dan 
dokumentasi. Untuk membantu proses wawancara, penentuan sumber data menggunakan teknik purposive sampling yaitu pengambilan sampel dengan pertimbangan tertentu sehingga informan yang memenuhi kriteria adalah Bapak Said Usman yakni seorang pengukir dari Pulau Penyengat yang telah menekuni pekerjaannya \pm 38 tahun lamanya. Alat-alat pendukung wawancara yang digunakan yaitu: buku catatan wawancara, tape dan video recorder dan camera.

Teknik analisis data yang digunakan yaitu analisis domain, analisis taksonomi, analisis komponensial dan analisis tema budaya. Pada analisis domain peneliti membuat gambaran umum dan menyeluruh tentang data untuk menjawab fokus penelitian. Peneliti akan melakukan analisis kecil dengan membaca literature yang berhubungan dengan penelitian dan menemukan beberapa kategori yang akan dijadikan pusat penelitian yaitu aktivitas mengukur, menghitung dan mendesain. Setelah itu melakukan analisis taksonomi yang menjabarkan domain-domain yang dipilih menjadi lebih rinci untuk mengetahui struktur internalnya. terfokus dan disajikan dalam bentuk out line. Setelah itu, peneliti melakukan analisis komponensial yaitu peneliti mengelompokkan setiap unsur tersebut kedalam setiap domain yang telah ditentukan. Dan selanjutnya akan difokuskan kedalam tema atau judul penelitian. Dalam hal ini, penelitian yang dilakukan agar dapat mendeskripsikan konsep matematika yang tertanam di balik ragam corak ukiran khas Melayu Kepulauan Riau.

Untuk menguji keabsahan data peneliti menggunakan perpanjangan pengamatan yang dilakukan dalam beberapa kali sesuai dengan waktu yang telah disepakati bersama. 44
Untuk membuat hubungan yang baik antara peneliti dan informan sehingga informan akan bisa semakin terbuka karena telah mempercayai peneliti. Selanjutnya peningkatan ketekunan yang cermat dan berkesinambungan. Dan yang terakhir adalah triangulasi teknik pengumpulan data dimana peneliti akan memeriksa hasil data yang diperoleh dari teknik observasi, wawancara, maupun dokumentasi.

\section{HASIL DAN PEMBAHASAN}

Seni ukir yang sudah lama tumbuh menjadi seni warisan Melayu merupakan satu peradaban yang paling tinggi nilainya karena ia merupakan suatu seni yang belum dipengaruhi oleh sembarang unsur-unsur lain dan sehati dengan masyarakat Melayu terutama di daerah Kepulauan Riau. Sebagai salah satu hasil seni rupa tradisi Melayu yang terunggul, seni ukir ini berisikan konsep-konsep keseimbangan alam dari segi komposisi, pemilihan corak dan bentuk ukiran dan semua komponen tersebut memiliki makna tersendiri.

Salah satunya ragam corak ukiran khas Melayu Kepulauan Riau yang biasanya menjadi hiasan di setiap bangunan atau rumah-rumah adat Melayu Kepulauan Riau. Corak khas tersebut sering dijadikan hiasan di salah satu bagian rumah seperti jendela, pintu, ventilasi, atap, maupun pagarnya.

Mengukir merupakan karya seni atau kerajinan diatas batu atau kayu dengan menggunakan alat dan teknik tertentu sehingga membentuk suatu bentuk cekung cembung bersambung yang estetis. Mengukir juga termasuk karya seni yang membutuhkan kesabaran dan ketelitian dalam proses pembuatannya.

Pada proses pembuatannya terdapat aktivitas matematis yang menjadi salah satu 
pelopor pengeksplorasian suatu karya seni yang merupakan suatu karya seni ukiran yang dihasilkan oleh Bapak Said Usman. Dan setelah melalui beberapa tahap analisis data dengan metode observasi, wawancara dan dokumentasi yang dilakukan peneliti, terbukti bahwa adanya aktivitas matematis yang terdapat pada ragam corak ukiran khas Melayu. Adapun aktivitas matematis tersebut meliputi aktivitas mengukur, aktivitas menghitung dan aktivitas mendesain.

Ketiga aktivitas tersebut digunakan dari segi proses pengukuran awal, perancangan corak hingga pada proses pengukiran corak di wadah ukirnya menghasilkan beberapa hasil corak ukiran dan ternyata terdapat beberapa konsep matematika yang terkandung dalam dalam ragam corak ukiran khas Melayu. Adapun konsep-konsep matematika yang terkandung pada ragam corak ukiran khas Melayu Kepulauan Riau yaitu:

Bangun datar dan bangun ruang yang dapat dilihat dari berbagai bentuk corak ukirannya yang memiliki panjang alas dan tinggi pada bentuk segitiga dan memiliki panjang dan lebar pada bentuk segiempat.
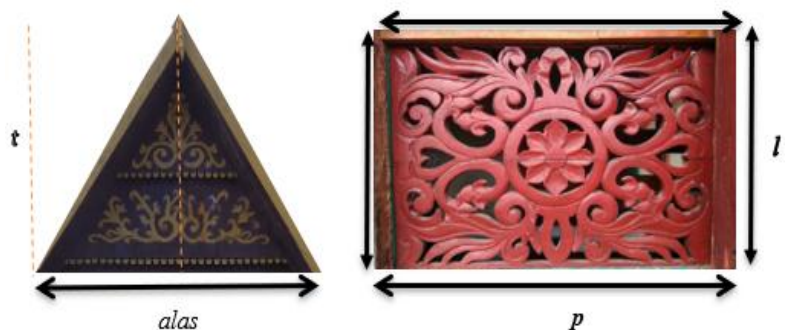

Gambar 1. corak singap/ bidai dan sekat jendela

Selanjutnya yaitu konsep pecahan. Pecahan pada ragam corak ukiran khas Melayu Kepulauan Riau ini terdapat pada hasil bentuk pengukiran corak yaitu mempunyai beberapa bagian motif dalam membentuk satu buah corak. Konsep pecahan biasanya sudah dipelajari di jenjang Sekolah Dasar (SD) dimana siswa dalam mengenal makna pecahan dengan memanfaatkan hal-hal disekeliling mereka. Contohnya adanya kepingan-kepingan corak yang dapat membentuk sebuah corak yang utuh, sehingga dengan adanya pembelajaran dalam konteks nyata dapat membantu siswa lebih cepat memahami makna pecahan.

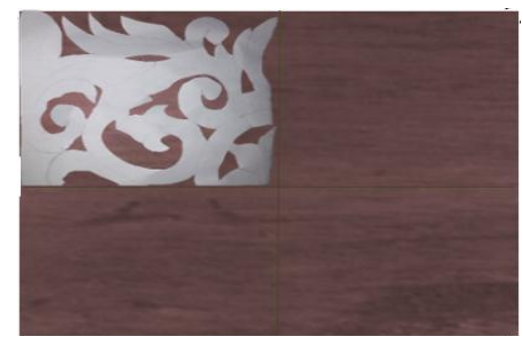

(a)

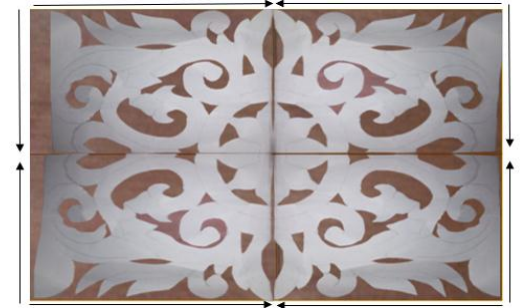

(b)

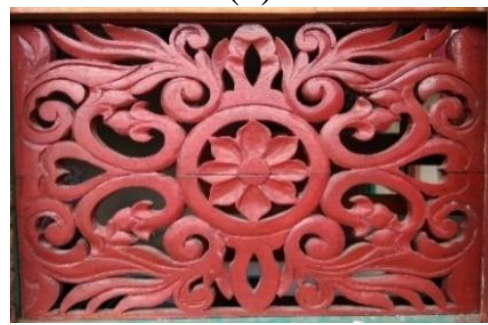

Gambar 2. (a) dan (b) corak sekat jendela

Konsep perbandingan terdapat pada aktivitas menghitung dalam pembuatan corak ukiran Melayu Kepulauan Riau yang memiliki perbandingan banyaknya jumlah pembuatan pada corak yang sama namun berbeda peletakkannya. Salah satu cara menunjukkan bahwa terdapat konsep perbandingan pada corak lebah bergayut yaitu dari banyaknya jumlah corak bergayut bagian depan rumah berbanding dengan banyaknya jumlah corak lebah bergayut pada bagian samping rumah karena berpengaruh pada ukuran panjang rumah bagian depan dan samping. Misalnya 
perbandingan antara 30 buah corak lebah bergayut dibagian depan rumah dengan 40 corak lebah bergayut yang sama untuk mengisi bagian samping rumah.

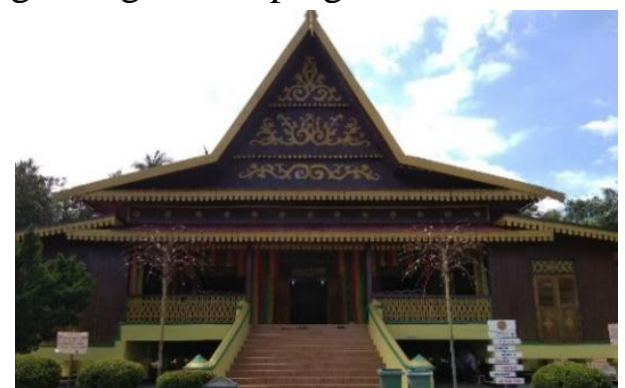

Gambar 3. (a) dan (b) corak sekat jendela

Kekongruenan yang terdapat pada bentuk corak ukiran yang dikatakan kongruen karena memiliki bentuk yang sama baik dari sisi ukuran panjang, lebar dan sudutnya. Konsep kekongruenan dan kesebangunan terdapat pada aktivitas mendesain corak ukiran Melayu Kepulauan Riau yang memiliki kesamaaan ukuran dan bentuk. Hal ini dapat ditemukan pada saat proses pembuatan corak pada ventilasi kuburan Raja Haji Fisabilillah, lebah bergayut, dan corak pagar. Salah satu cara untuk menunjukkan bahwa terdapat konsep kekongruenan pada corak ukiran yaitu dari desain corak yang dibuat pengukir kemudian diberikan tindakan, apakah dicerminkan, digeser, atau diputar sehingga dengan proses ini, maka diperoleh corak lainnya pada posisi lain yang memiliki ukuran dan bentuk yang sama dengan corak ukiran semula.

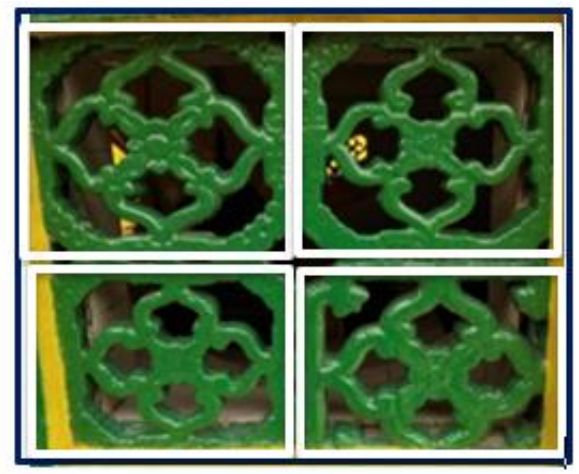

Gambar 4. Corak ventilasi kuburan R. H. Fisabilillah

Konsep simetri terdapat pada pembuatan corak ukiran. Pengukir menerapkan konsep simetri ini dalam pendesainan corak sehingga liukan-liukan corak yang dibuat akan sama sisi kiri dan kanannya. Konsep simetri dari ragam corak ukiran khas Melayu ini terdapat pada aktivitas mendesain. Konsep simetri ini merupakan salah satu teknik yang diterapkan oleh pengukir dalam pembuatan corak ukiran.

Dalam proses sebelum pegukiran, wadah ukirnya diberikan garis vertikal yang membagi dua wadah tersebut sehingga memiliki besar sisi yang sama. Lalu penciplakan desain corak yang sudah dirancang dikarton dengan sedemikian rupa diletakkan diatas sisi kanan wadah dengan batasan garis vertikal tadi. Selanjutnya untuk melengkapi corak dalam satu wadah tersebut, desain corak tadi dibalik kearah lawannya yaitu bagian kiri pada wadah pengukirannya. Sehingga corak yang dihasilkan akan sama besar, sama panjang dan juga corak motifnya.

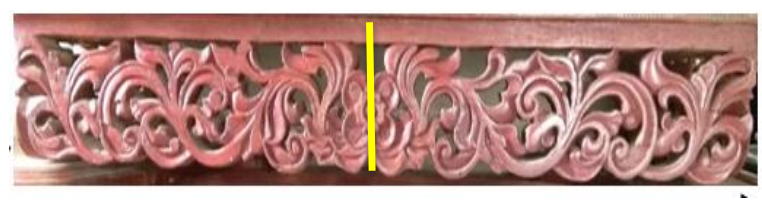

Gambar 5. Corak meja televisi

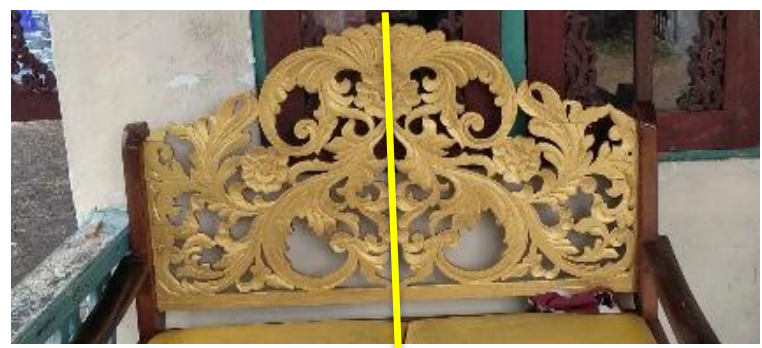

Gambar 6. Corak sandaran kursi

Transformasi geometri juga terdapat pada ragam corak ukiran khas Melayu. 
Konsep transformasi ini merupakan salah satu teknik yang digunakan pengukir untuk membuat satu buah corak yang memiliki corak yang sama setiap sisinya, hanya saja perbedaannya hanya terletak pada teknik peletakkan corak. Pada jenjang dasar pembelajaran konsep transformasi ini hanya bersifat pencerminan ataupun simetri. Di jenjang selanjutnya mengalami penambahan konsep transformasi yaitu terdiri dari translasi (perpindahan), refleksi (pencerminan), rotasi (perputaran) dan dilatasi (perbesaran). Siswa akan mengenal dan memahami makna-makna dan perbedaan setiap konsep pada transformasi.

Namun pada ragam corak ukiran khas melayu Kepulauan Riau ini hanya mengandung tiga konsep transformasi yaitu konsep translasi, refleksi dan rotasi. Untuk konsep translasi digunakan dalam pembuatan corak ukiran Melayu. Dengan memindahkan atau menggeser sketsa corak ukiran Melayu ke posisi tertentu, tentunya cukup jelas menggambarkan bahwa konsep translasi telah diterapkan dalam pembuatan corak ukiran Melayu yaitu corak lebah bergayut yang letaknya bergantungan di bawah atap dan juga corak pada pagar Melayu. Sebagai contoh corak bisa dilihat pada gambar berikut.

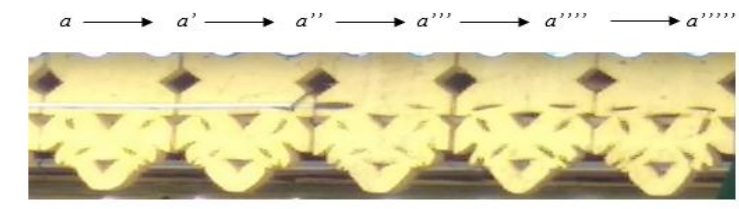

Gambar 7. Corak lebah bergayut (translasi)

Sedangkan konsep refleksi terdapat pada teknik pembuatan sehingga terlihat pada hasil ukirannya mengandung sifat refleksi. Misalnya seperti pembuatan corak pada gambar berikut pengukir cukup membuat sketsa motif $a$, yang selanjutnya sketsa ini ditaruh disebelah kanan, bawah atau posisi tertentu lainnya yang akhirnya akan memperoleh corak ukiran Melayu yang utuh.

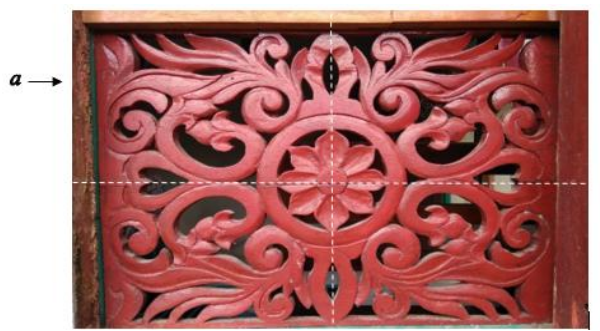

Gambar 8. Corak sekat jendela (refleksi)

Dan yang terakhir adalah konsep rotasi pada pembuatan corak ukiran Melayu juga dapat dikaitkan konsep rotasi pada bangun datar. Sebagai contoh, pada gambar berikut yang merupakan corak yang dibuat narasumber dan berada di bagian tengah sisi atas pintu. Teknik yang digunakan pada corak tersebut yaitu teknik tata letak dengan cara diputar yang membuat corak tersebut menjadi terlihat lebih berbeda namun ternyata mengandung corak yang sama. Terlihat pada motif $a$ terlebih dahulu dicerminkan terhadap sumbu cermin vertikal sehingga diperoleh $a^{\prime}$, $a^{\prime}$ ini selanjutnya diputar $180^{\circ}$ sehingga diperoleh $a^{\prime \prime}$. Dari proses tersebut, diperoleh Seperti pada gambar berikut.

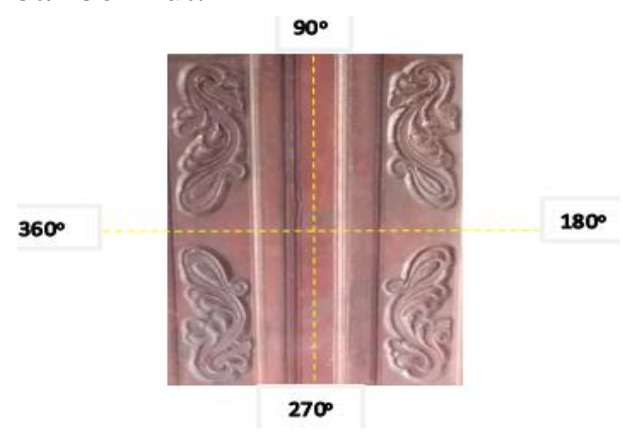

Gambar 9. Corak pintu (rotasi)

\section{SIMPULAN DAN SARAN}

Berdasarkan hasil penelitian dan pembahasan dengan teknik observasi, wawancara dan dokumentasi, dapat disimpulkan bahwa terdapat konsep matematika sekolah dalam ragam corak 
ukiran khas Melayu Kepulauan Riau yang dapat diterapkan dalam pembelajaran matematika di sekolah yaitu: konsep bangun datar dan bangun ruang, pecahan, perbandingan, kongruenan, simetri dan transformasi geometri.

\section{REFERENSI}

Edy, T. 2013. Pengembangan pembelajaran matematika sekolah dengan pendekatan etnomatematika berbasis budaya lokal sebagai upaya untuk meningkatkan kualitas pembelajaran matematika di sekolah. In Prosiding Seminar Nasional Matematika Dan Pendidikan Matematika. Jurusan Pendidikan Matematika FMIPA UNY. Retrieved From Http://Eprints.Uny.Ac.Id/10748/
Laurens, Theresia. 2016. Analisis etnomatematika dan penerapannya dalam meningkatkan kualitas pembelajaran. Jurnal Prodi Pendidikan Matematika STKIP PGRI Sumbar, 3(1).

Mulyasa, E. 2015. Pengembangan dan implementasi kurikulum 2013. PT. Remaja Rosdakarya: Bandung

Prabawati, M. N. (2016). Etnomatematika masyarakat pengrajin anyaman rajapolah kabupaten tasikmalaya. Infinity Journal, 5(1), 25-31 Rachmawati, Inda. 2012. Eksplorasi etnomatematika masyarakat sidoarjo. Jurnal. Surabaya. Fakultas Matematika Dan Ilmu Pengetahuan UNESA 